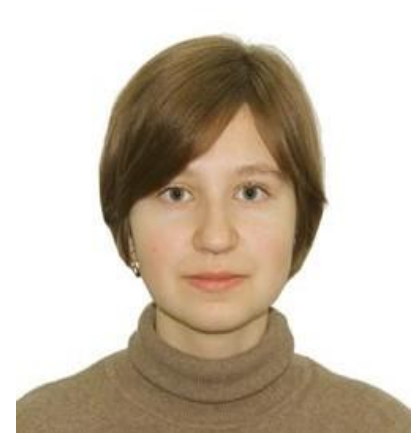

\section{ИЗМЕРЕНИЕ СТЕПЕНИ ЗАГРЯЗНЕННОСТИ РАДИОАКТИВНЫМИ ВЕЩЕСТВАМИ ОБЪЕКТОВ ЖИЛОЙ ЗАСТРОЙКИ И ОБЩЕСТВЕННЫХ ЗДАНИЙ}

\author{
А.Н. Назаркина, студентка, \\ e-mail: nazarkina-alexsandra@mail.ru \\ ФГБОУ ВО «Калининградский государственный \\ технический университет» \\ Л.Н. Серегина, доц., \\ e-mail: sereginamila57@mail.ru \\ ФГБОУ ВО «Калининградский государственный \\ технический университет»
}

Данное исследование посвящено необходимости на регулярной основе осуществлять радиационный дозиметрический контроль уровня радиации в общественных зданиях, сооружениях, а также в жилых домах.

В статье приводятся результаты экспериментальных исследований радиационного фона на объектах г. Калининграда. Радиационная обстановка исследовалась путем замеров мощности экспозиционной дозы гамма-излучения с помощью профессионального портативного дозиметра МКС-05 ТЕРРА. По ходу исследования проводились замеры в учебных учреждениях, общественных зданиях и жилой квартире, при этом учитывались показания гамма-фона на прилегающих территориях.

На основании полученных результатов сделаны выводы о наличии или отсутствии радиационной опасности, о соответствии жилых квартир и общественных зданий санитарноэпидемиологическим требованиям, а также санитарно-гигиеническим нормам. По итогам исследования даны рекомендации по снижению уровня радиации.

Ключевые слова: радиационная безопасность, ионизирующее излучение, мощность эквивалентной дозы, радиационный фон, дозиметр, уровень радиации

\title{
ВВЕДЕНИЕ
}

В современных условиях жизни измерение радиационного фона стало одним из необходимых мероприятий по обеспечению безопасности на различных объектах.

Контроль радиационного фона необходим в медицинских, учебных учреждениях, на промышленных объектах, даже в частных домах и жилых квартирах. Наличие радона, рентгеновских альфа-, бета-, гамма-потоков может стать причиной существенного вреда здоровью человека. Поэтому точная информация об уровне радиационного излучения и знание свойств радиации позволит свести к минимуму связанную с ней опасность.

\section{ОБЪЕКТ ИССЛЕДОВАНИЯ}

Объектом исследования в данной научно-исследовательской работе является измерение уровня радиации на объектах жилой застройки и общественных зданиях.

Для рассмотрения объекта исследования необходимо изучить на основе научной и методической литературы содержание понятия о радиоактивности и ионизирующем излучении.

По определению радиоактивность - это самопроизвольные превращения неустойчивых атомных ядер в ядра других элементов (ядерный распад) и сопутствующие излучения, которые формируют радиационный фон, представляющий собой ионизирующее излучение 
(ИИ), действующее на человека на поверхности Земли как от естественных источников космического и земного происхождения, так и от искусственных (техногенных) источников.

По статистике основную часть облучения ионизирующим излучением человек получает от естественных источников.

Естественное ионизирующее излучение создает радиационный фон, образуемый космическим излучением и излучением естественных радионуклидов, которые могут находиться в грунте и строительных материалах.

В обычных условиях естественное ИИ создает малые дозы облучения от 0.12 до 0.2 микрозиверт в час.

Как показывает практика, в зданиях доза облучения оказывается существенно больше.

Наибольшее значение имеют дозы, создаваемые радоном, который является радиоактивным бесцветным газом, без вкуса и запаха. Он находится в воздухе и, как следствие, в жилых помещениях, где человек проводит большую часть своей жизни. Главными источниками попадания радона являются:

- водопроводная вода, так как радон способен растворяться в воде и из нее поступать в воздух помещения;

- бытовой газ;

- строительные материалы (мрамор, гранит, щебень, графит, пемза и др.);

- почва под зданиями, поскольку радон способен попадать в здания через щели в фундаменте, и так как радон тяжелее воздуха, его концентрация выше на нижних этажах.

Интересно, что большую часть дозы облучения от радона человек получает, находясь продолжительное время в закрытом, непроветриваемом помещении. Поэтому необходимо регулярно проветривать помещение, так можно снизить концентрацию радона.

Также при планировании строительства необходимо использовать радиационнобезопасные стройматериалы.

Если говорить об искусственных (техногенных) источниках ионизирующего излучения, то это любые источники, созданные деятельностью человека.

Здесь индивидуальные показатели доз облучения сильно разнятся, так как малое количество людей контактирует с искусственными источниками. Преимущество этих доз лишь в том, что их обычно легче сдерживать, чем дозы облучения, связанные с естественными источниками.

Области, где люди сталкиваются с искусственными источниками, разнообразны:

- использование в медицине рентгеновского излучения;

- выбросы радиоактивных отходов ядерной промышленности;

- испытания ядерного оружия;

- научные исследования и т.д.

Стоит отметить, что мобильные телефоны, Wi-Fi-станции и другие устройства связи не являются источниками ионизирующего излучения, поскольку работают в микроволновом диапазоне, частота которого ниже, чем частота видимого света.

В итоге получается, что большинство радиоактивного облучения человек получает от естественных источников (рис. 1). 


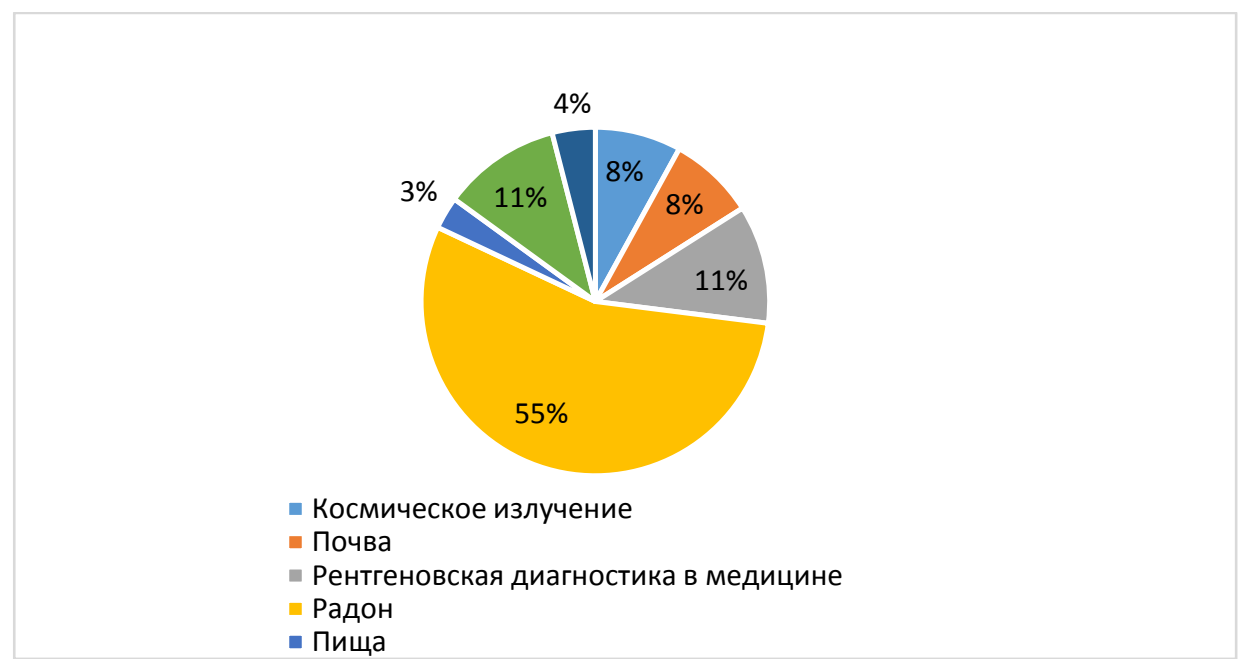

Рисунок 1 - Доля радиоактивного облучения от естественных и искусственных источников

Воздействие радиации на человека называют облучением, оно происходит вследствие передачи энергии радиации клеткам организма. Облучение может вызывать нарушения обмена веществ, злокачественные опухоли, лучевую болезнь, бесплодие и т.д.

Из-за опасности облучения в общественных зданиях и сооружениях должен осуществляться радиационный дозиметрический контроль. Радиационный контроль - важный элемент обеспечения безопасности для жильцов, персонала, посетителей и других лиц, которые будут пользоваться планируемым объектом.

Стоит отметить, что в сравнении со многими другими возможными опасностями радиацию невозможно почувствовать и увидеть.

Определить ее уровень можно только специальными приборами.

Для обнаружения ионизирующего излучения используют приборы, которые называются дозиметры. Дозиметры - это приборы для измерения доз ионизирующих излучений или величин, которые могут получить люди за время пребывания на радиоактивно зараженной местности.

В исследовательской работе был задействован профессиональный портативный дозиметр МКС-05 ТЕРРА.

Как уже отмечалось, дозиметр измеряет дозы ионизирующего излучения. Доза, полученная в единицу времени, называется мощностью дозы.

Это величины, которые применяются, чтобы оценить уровень воздействия ионизирующего излучения на организм человека.

Контролируемой величиной в зданиях и помещениях является мощность эквивалентной дозы гамма-излучения, которая оценивается показателем микрозиверт в час (мкЗв/ч). Она «не должна превышать 0,3 мкЗв/ч с учетом фона» [1].

Данные о естественном радиационном фоне г. Калининграда были взяты с сайта Калининградского центра по гидрометеорологии и мониторингу окружающей среды, который осуществляет стационарный радиоэкологический мониторинг путем измерения мощности эквивалентной дозы гамма-излучения на семи станциях основной сети ежедневно. Естественный фон г. Калининграда, согласно данным, составляет 0,12 мкЗв/ч, значение находится в пределах естественных значений [2].

\section{ЦЕЛЬ, ЗАДАЧИ ИССЛЕДОВАНИЯ}

Целью научно-исследовательской работы было: определить уровень радиационного фона на различных объектах г. Калининграда и сделать выводы о наличии или отсутствии радиационной опасности. 
Для достижения поставленной цели были сформулированы следующие задачи:

- на основе анализа научной и методической литературы установить содержание понятий о явлении радиоактивности и ионизирующем излучении;

- освоить навыки практического измерения уровня $\gamma$-излучения с помощью специального прибора дозиметра МКС-05 ТЕРРА;

г. Калининграда;

- провести измерения уровня радиационного фона на различных объектах

- сделать выводы о наличии или отсутствии радиационной опасности;

- дать рекомендации по снижению уровня радиации.

\section{МЕТОДЫ ИССЛЕДОВАНИЯ}

В соответствии с целями работы были проведены измерения радиационной обстановки в жилой квартире, в учебных учреждениях, а также в общественных местах г. Калининграда. (рис. 2)

Измерение уровня радиации проводилось с помощью дозиметра МКС-05 ТЕРРА

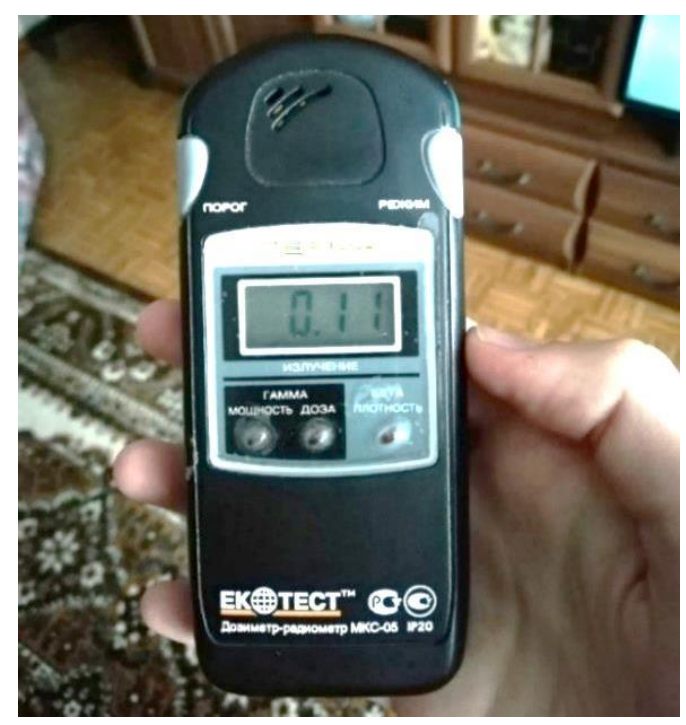

Рисунок 2 - Дозиметр МКС-05 ТЕРРА

Излучения регистрируются с помощью газоразрядного счетчика Гейгера-Мюллера.

Для того чтобы включить дозиметр, нужно кратковременно нажать кнопку «Режим» в правом верхнем углу. Сразу после включения дозиметр работает в режиме измерения мощности эквивалентной дозы, это можно понять по мигающему огоньку напротив соответствующей надписи «Мощность». При регистрации каждого гамма-кванта также прибор издает звуковые сигналы. Держать дозиметр необходимо датчиком вниз, то есть задней стороной прибора к источнику излучения. В помещении делают замеры на высоте 1.0 м от пола, через несколько секунд на индикаторе высвечивается результат. Для включения остальных режимов работы дозиметра последовательно нажимают кнопку «Режим». Технические характеристики дозиметра МКС-05 ТЕРРА представлены в табл. 1.

Таблица 1 - Технические характеристики дозиметра МКС-05 ТЕРРА

\begin{tabular}{|c|c|}
\hline Параметры & Значения \\
\hline Тип детектора & Счетчик Гейгера СБМ-20 \\
\hline $\begin{array}{c}\text { Приблизительное время выхода в «рабо- } \\
\text { чий» режим }\end{array}$ & $40-60 \mathrm{c}$ \\
\hline $\begin{array}{c}\text { Диапазон измерения мощности эквива- } \\
\text { лентной дозы (МЭД) гамма-излучения }\end{array}$ & $0,1-9999$ мкЗв/ч \\
\hline Погрешность измерения МЭД & $+(-) 15 \%$ \\
\hline
\end{tabular}


Величина, в которой измерялась мощность радиационного фона, - мкЗв/ч (микрозиверт в час).

При проведении дозиметрических измерений были соблюдены инструкции, изложенные в технической документации на прибор, и использованы утвержденные методики измерения.

Для увеличения надежности дозиметрического контроля было проведено несколько измерений (не менее трех), а затем посчитано среднее арифметическое. Также учитывался естественный радиационный фон снаружи.

\section{РЕЗУЛЬТАТЫ ИССЛЕДОВАНИЯ}

В первую очередь были проведены измерения в жилой квартире многоквартирного дома на седьмом этаже. Здесь была проверена теория о снижении концентрации радона при проветривании помещений.

Таким образом, в непроветриваемых помещениях квартиры, особенно где течет вода и используется бытовой газ, радиационный фон оказался выше. Все показатели оказались в пределах нормы. После проветривания при повторном измерении наблюдалось снижение радиационного фона. Значит, регулярное проветривание снижает концентрацию радона. Данные измерений приведены в табл. 2.

Таблица 2 - Результаты измерения уровня радиации в жилой квартире

\begin{tabular}{|c|c|c|}
\hline Помещение & $\begin{array}{c}\text { Измерение до проветривания, } \\
\text { мк3в/час }\end{array}$ & $\begin{array}{c}\text { Измерение после проветривания, } \\
\text { мк3в/час }\end{array}$ \\
\hline ванная & 0,14 & 0,13 \\
\hline кухня & 0,20 & 0,14 \\
\hline гостиная & 0,09 & 0,08 \\
\hline комната & 0,13 & 0,10 \\
\hline
\end{tabular}

Следом были проведены измерения в Балтийской государственной академии рыбопромыслового флота (БГАРФ). Измерения проходили в 1-м корпусе (табл. 3), 2-м корпусе (табл. 4), 3-м корпусе (табл. 5), а также в физкультурно-оздоровительном комплексе (табл. 6). В целом все результаты измерений гамма-фона находились в пределах нормы. Самый высокий показатель был зафиксирован в 3-м корпусе (0,22 мкЗв/час).

Таблица 3 - Результаты измерения уровня радиации 1 корпуса БГАРФ

\begin{tabular}{|c|c|}
\hline Помещение & Измерение, мкЗв/час \\
\hline первый этаж & 0,18 \\
\hline библиотека & 0,18 \\
\hline цокольный этаж & 0,15 \\
\hline
\end{tabular}

Таблица 4 - Результаты измерения уровня радиации 2 корпуса БГАРФ

\begin{tabular}{|c|c|}
\hline Помещение & Измерение, мк3в/час \\
\hline первый этаж & 0,14 \\
\hline четвертый этаж & 0,13 \\
\hline кабинет на 4-м этаже & 0,12 \\
\hline
\end{tabular}

Таблица 5 - Результаты измерения уровня радиации 3 корпуса БГАРФ

\begin{tabular}{|c|c|}
\hline Помещение & Измерение, мк3в/час \\
\hline второй этаж & 0,22 \\
\hline лестничная площадка & 0,22 \\
\hline кабинет на 4-м этаже & 0,12 \\
\hline
\end{tabular}


Таблица 6 - Результаты измерения уровня радиации физкультурно-оздоровительного комплекса БГАРФ

\begin{tabular}{|c|c|}
\hline Помещение & Измерение, мкЗв/час \\
\hline первый этаж & 0,16 \\
\hline раздевалка & 0,12 \\
\hline преподавательская & 0,16 \\
\hline
\end{tabular}

Следующим учебным заведением для проверки был выбран Калининградский государственный технический университет. Были проведены замеры в главном корпусе (табл. 7) и в корпусе на ул. Профессора Баранова, 43 (табл. 8).

Таблица 7 - Результаты измерения уровня радиации главного корпуса КГТУ

\begin{tabular}{|c|c|}
\hline Помещение & Измерение, мкЗв/час \\
\hline первый этаж & 0,15 \\
\hline второй этаж & 0,22 \\
\hline третий этаж & 0,18 \\
\hline
\end{tabular}

Таблица 8 - Результаты измерения уровня радиации корпуса КГТУ на ул. Профессора Баранова, 43

\begin{tabular}{|c|c|}
\hline Помещение & Измерение, мкЗв/час \\
\hline первый этаж & 0,10 \\
\hline второй этаж & 0,18 \\
\hline третий этаж & 0,14 \\
\hline
\end{tabular}

И последним учебным заведением на проверку был Институт экономики и менеджмента БФУ им. И. Канта (табл. 9). Здесь также все показатели оказались в пределах установленной нормы.

Таблица 9 - Результаты измерения уровня радиации Института экономики и менеджмента БФУ им. И. Канта

\begin{tabular}{|c|c|}
\hline Помещение & Измерение, мк3в/час \\
\hline первый этаж & 0,11 \\
\hline второй этаж & 0,14 \\
\hline кабинет на 2-м этаже & 0,12 \\
\hline
\end{tabular}

Далее проверка радиационного фона проходила в общественных местах. В торговом центре «Вестер» (табл. 10) все показатели были в пределах нормы.

Таблица 10 - Результаты измерения уровня радиации торгового центра «Вестер»

\begin{tabular}{|c|c|}
\hline Помещение & Измерение, мкЗв/час \\
\hline первый этаж & 0,12 \\
\hline второй этаж & 0,10 \\
\hline магазин «Семья» & 0,13 \\
\hline
\end{tabular}

Самый высокий показатель был в торгово-развлекательном центре «Европа» (табл. 11) на цокольном этаже. Скорее всего, это связано с тем, что основной источник радона - это грунт под зданием, а цокольный этаж находится ближе к поверхности земли. 
Таблица 11 - Результаты измерения уровня радиации торгово-развлекательного центра «Европа»

\begin{tabular}{|c|c|}
\hline Помещение & Измерение, мк3в/час \\
\hline первый этаж & 0,11 \\
\hline второй этаж & 0,08 \\
\hline магазин одежды & 0,12 \\
\hline кафе «Макдоналдс» & 0,12 \\
\hline 3-й этаж, возле кинотеатра & 0,10 \\
\hline цокольный этаж & 0,17 \\
\hline
\end{tabular}

\section{ЗАКЛЮЧЕНИЕ}

По итогу выполненных замеров отклонений от нормы на исследуемых объектах г. Калининграда не выявлено.

Самыми минимальными величинами гамма-фона (0,11 мкЗв/ч) оказались показания в жилой квартире, если учитывать данные в квартире после проветривания.

Если же не учитывать квартиру после применяемых мер по снижению гамма-фона, то минимальные величины $(0,12$ мкЗв/ч) были выявлены в торгово-развлекательном центре «Европа», в торговом центре «Вестер» и в Институте экономики и менеджмента БФУ им. И. Канта.

Более высокое значения гамма-фона $(0,18$ мкЗв/ч) было зафиксировано в главном корпусе Калининградского государственного технического университета. Возможной причиной высокого значения мощности экспозиционной дозы служит содержание в строительных материалах природных радионуклидов.

Среднее значение гамма-фона на исследуемых объектах составило 0,12 мкЗв/ч, что соответствует естественному радиационному фону г. Калининграда.

Таким образом, проведенные измерения радиационного фона на исследуемых объектах г. Калининграда показали, что значения гамма-фона находятся в пределах допустимых норм. Отсутствие превышения предела означает, что радиационная безопасность обеспечена.

Из проделанной работы можно сделать вывод о том, что:

- человек чаще подвергается воздействию природных источников радиации (газа радона и стройматериалов);

- радиационный фон гораздо меньше на улице, чем дома и в общественных зданиях;

- радиационный фон в помещениях снижается после проветривания.

Для поддержания допустимого уровня радиации желательно следовать следующим рекомендациям:

- частое проветривание, позволяющее избежать скопления радона;

- контролировать качество изоляции фундамента;

- при строительстве проверять качество и состав строительных материалов.

Кроме того, может быть рекомендована окраска внутренних поверхностей стен масляной краской или оклейка их воздухонепроницаемым слоем.

Также с целью уменьшения воздействия радиации необходимо распространять знания радиационной гигиены и безопасности и рекомендовать населению приобретать бытовые дозиметрические приборы.

Практическое применение данных исследований.

Для выпускников по программе образования бакалавриата 20.03.01 «Техносферная безопасность» профиля «Защита в чрезвычайных ситуациях» (год начала подготовки по учебному плану 2020 г.) поиск наиболее современных и эффективных методов обучения в данном направлении является актуальным.

Внедряя практическую работу в учебный процесс с использованием данного прибора и методики работы с ним, выпускник получит способность:

- ориентироваться в основных методах и системах обеспечения техносферной безопасности; 
- обоснованно выбирать известные устройства, системы и методы защиты человека и окружающей среды от опасностей;

- принимать участие в эксплуатации средств защиты;

- организовывать и проводить обслуживание технических средств.

\title{
СПИСОК ЛИТЕРАТУРЫ
}

1. МУ 2.6.1.2838-11. 2.6.1. от 28.02.2011 г. Ионизирующее излучение, радиационная безопасность. Радиационный контроль и санитарно-эпидемиологическая оценка жилых, общественных и производственных зданий и сооружений после окончания их строительства, капитального ремонта, реконструкции по показателям радиационной безопасности.

2. Калининградский центр по гидрометеорологии и мониторингу окружающей среды: [сайт]. URL: http://meteo39.ru/monitoring/radiatsiya.html.

\section{MEASURING THE DEGREE OF CONTAMINATION BY RADIOACTIVE SUB- STANCES OF RESIDENTIAL BUILDINGS AND PUBLIC BUILDINGS}

\author{
A.N. Nazarkina, student, \\ e-mail: nazarkina-alexsandra@mail.ru \\ Kaliningrad State Technical University \\ L.N. Seregina, Associate Professor, \\ e-mail: sereginamila57@mail.ru \\ Kaliningrad State Technical University
}

This study focuses on the need to carry out radiation dosimetric monitoring of radiation levels in public buildings, structures, and in residential buildings on a regular basis.

The article presents the results of experimental studies of the radiation background at the facilities of the city of Kaliningrad. The radiation situation was investigated by measuring the exposure dose rate of gamma radiation using a professional portable dosimeter MKS-05 TERRA. In the course of the study, measurements were taken in educational institutions, public buildings and a residential apartment, while taking into account the readings of the gamma background in the adjacent territories.

Based on the results obtained, conclusions were drawn about the presence or absence of radiation hazard, about the compliance of residential apartments and public buildings with sanitary and epidemiological requirements, as well as sanitary and hygienic standards. Based on the results of the study, recommendations were made to reduce the level of radiation.

Key words: radiation safety, ionizing radiation, exposure dose rate, background radiation, dosimeter, radiation leve. 